\title{
LOCAL SCOUR AROUND THE PIERS OF THE SHIMANTO RIVER BRIDGE
}

\author{
Ricardo de ARAGÃO1, Akihiro KADOTA² ${ }^{2}$, Koichi SUZUKI ${ }^{2}$ \\ ${ }^{1}$ Member of JSCE, Ph.D. Student, Dept. of Civil and Environmental Engineering, Ehime University \\ (3 Bunkyo-cho, Matsuyama-shi, Ehime-ken, Japan) \\ ${ }^{2}$ Member of JSCE, Dr. Eng., Dept. of Civil and Environmental Engineering, Ehime University \\ (3 Bunkyo-cho, Matsuyama-shi, Ehime-ken, Japan)
}

\begin{abstract}
To analyze the scour process around the piers of Shimanto River Bridge (Japan), experiments using a tilting flume, uniform and non-uniform mixture, cylindrical and compound pier models were conducted. The piers were subjected to different discharges, and three different attack angles. A dimensionless number, $N s$, was related to the relative scour depth $(Z s / D)$ at upstream face of the piers. The results enabled the determination of the representative diameter of the non-uniform mixture and a linear curve between $Z s / D$ and $N s$. For both pier models, no clear tendency was found between $Z s / D$ and flow depth. The attack angles led to scour depths that varied according to the grade of alignment to the flowing water.
\end{abstract}

Key Words: Shimanto River, scour process, sediment mixture, laboratory experiments

\section{INTRODUCTION}

The scour process at man-made structures located inside a river channel has received much attention, because the importance of the knowledge of this phenomenon to a proper design and maintenance of these structures, and for the safety of the users. Among the objectives aimed by the researchers, the estimation of scour depth at these structures is the principal concern. Bridge foundations (piers and abutments) are the most common structures made by men. They partially obstruct the cross section area of the river channel, change the flow pattern, which increases the velocity around them, leading to the removal of material from the riverbed. This process is known as local scour and is a component of the natural phenomenon named total scour. Local scour is affected by several variables such as flow depth and velocity, grain size of the riverbed, pier size and shape, turbulence, vortices, type of the sediment transport, among others. The effect of these factors on the maximum scour depth makes the accurate evaluation of the scour depth an aim difficult to be attained. This problem is usually overcome through empirical formulas, which are based on laboratory experiments and validated with field observation, when available. Nevertheless, most of the usable formulas in the literature consider the local scour process occurring on a uniform sand bed, which is rather different from what occurs in a real riverbed. The realistic approach should be the one which takes into account the diversity of sediment size on a riverbed through the use of uniform and non-uniform sand mixtures. For bridge foundations located in rivers subject to frequent floods, the scour process becomes even more complex. That is what occurs at the piers of the Shimanto River Bridge (Shikoku Island, Japan).

In the present work, laboratory experiments using uniform and non-uniform sand and pier models have been conducted. These experiments considered the pier shape, the size of bed material, and pier alignment to flow pattern found at Shimanto River Bridge, whose foundation has been subject to an advanced localized scour. The data from the experiments are analyzed in the light of the main factor affection on the scouring and a relationship for the determination of relative scour depth at single cylindrical piers is proposed.

\section{SHIMANTO RIVER AND THE SCOUR PROCESS AT BRIDGE FOUNDATION}

The Shimanto River is located on Shikoku island, Japan, and flows down around 1,200 $\mathrm{m}$ from the south flank of the Mt. Irazu, in Ehime Prefecture, to the Pacific Ocean, at the Tosa Bay, in Kochi Prefecture (Fig. 1). 


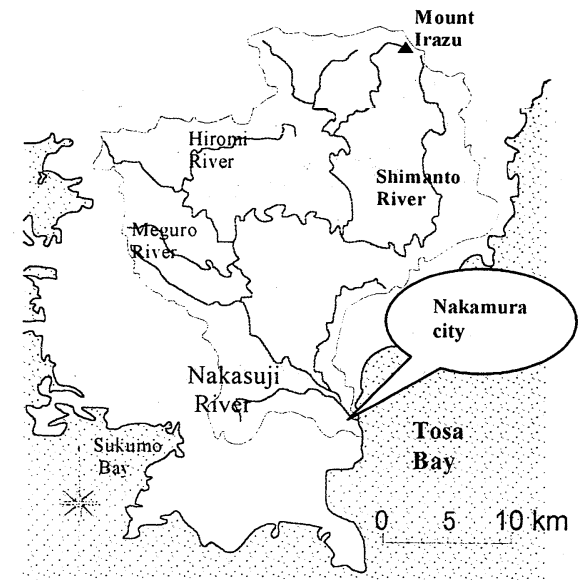

Fig. 1. Shimanto River drainage basin.

The drainage basin area is around $2,270 \mathrm{~km}^{2}$, of which $90 \%$ is located on mountain region. The river thalweg is approximately $196 \mathrm{~km}$ in length, sloping steeply toward the river mouth. The riverbed is basically formed of a sand-boulders mixture, in a wide range of grain size. The area has become a rainy zone due to typhoons, which hit that side of the island every year, causing floods and damages. The annual mean rainfall is around $2,700 \mathrm{~mm}$, which exceeds the nationwide mean of $1,800 \mathrm{~mm}$. The annual mean flow discharge is equal to 125 $\mathrm{m}^{3} / \mathrm{s}$, but can reach amounts up to $13,000 \mathrm{~m}^{3} / \mathrm{s}$ in case of flood events.

\section{(1) Shimanto River Bridge}

The Shimanto River Bridge is a pillared truss iron bridge, located in Nakamura City, at $9.5 \mathrm{~km}$ upstream the estuary, being used as a roadbridge (Fig. 2). The bridge is $508 \mathrm{~m}$ in length, and is founded by 13 compound piers (eight are thick and five are thin). Two cylindrical piers joined by a concrete ring ( $1 \mathrm{~m}$ thick) at the base compose the thick piers (Fig. 3). The total length of this set is equal to $11.2 \mathrm{~m}$. Including the length of the brim $(0.35 \mathrm{~m})$, the width of the base, near the ring, is 4.7 $\mathrm{m}$. The span between the compound piers is about $55 \mathrm{~m}$. From the left side bank these piers are named as $\mathrm{P} 1$ to $\mathrm{P} 13$.

\section{(2) The Scour Process}

The successive floods in the river basin have caused not only damage to fields and buildings, but also a localized scour process at the piers of the Shimanto River Bridge. On July 17 ${ }^{\text {th }}, 2001$ a field observation was conducted at the site, resulting in a more accurate knowledge about the bridge and the scour process around its piers. From that investigation, it was learned that an advanced scour process is occurring at $30 \mathrm{~m}$ downstream of $\mathrm{P} 6$ and P7. Also, a meander conveys the flow toward these piers, intensifying the scour process (Figs. 2, 4, 5).

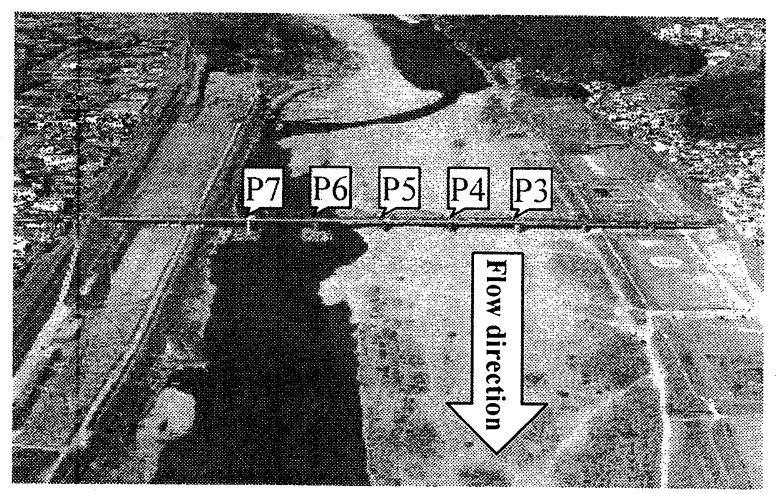

Fig. 2 Shimanto River Bridge.

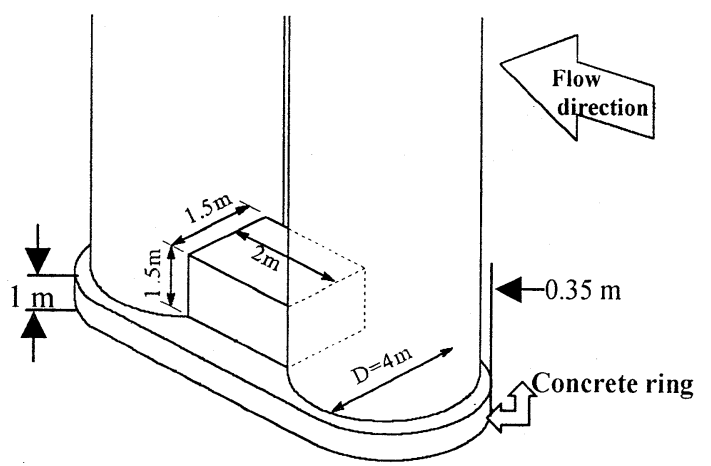

Fig.3 Shape of the compound pier of Shimanto River Bridge.

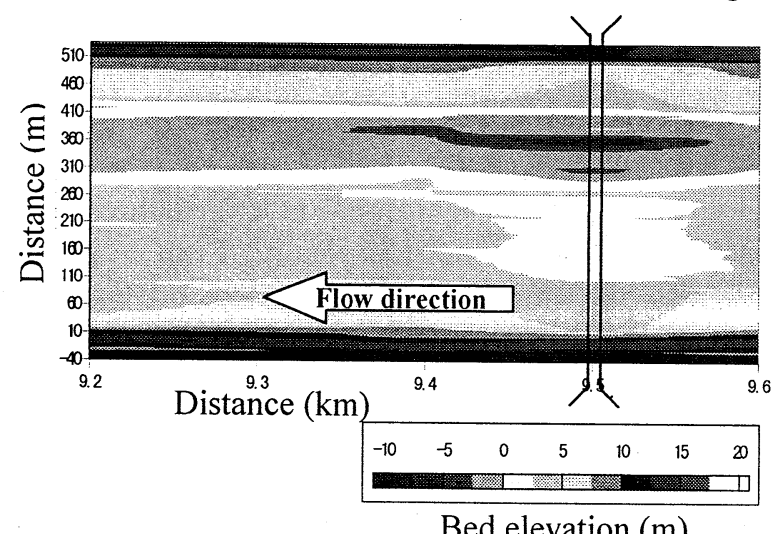

Fig.4 Riverbed elevation near the bridge.

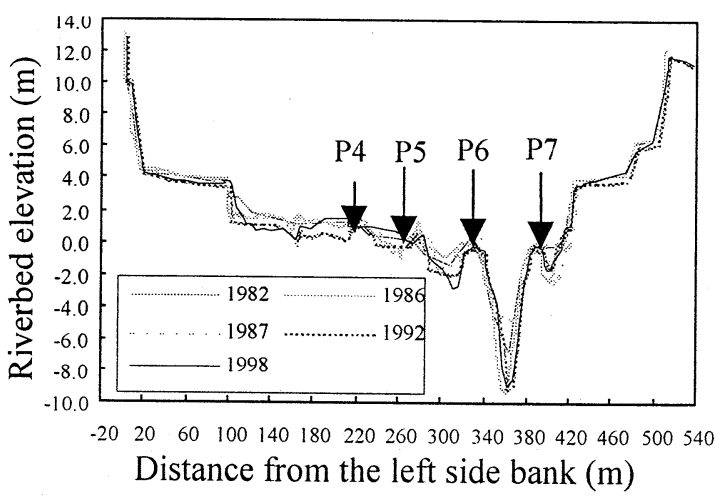

Fig. 5 Riverbed cross-section near the bridge.

By means of an underwater observation and based on previous data records, a cross section view of this spot was depicted (Fig. 5).

Moreover, a localized scour is taking place around P3, P4, and P5. From borings near P4 and P5, 
material of the riverbed was collected, enabling the determination of the sediment size distribution. This material belongs to the sand-boulders class in which the $D_{16}=6 \mathrm{~mm}, D_{50}=20 \mathrm{~mm}, D_{8 t}=50 \mathrm{~mm}$, giving a standard deviation, $\sigma_{g}=\left(D_{8 \downarrow} / D_{I \sigma}\right)^{1 / 2}$, equal to 2.88 $\mathrm{mm}$. This information will be used as base for determining the range of the sediment that should be applied to the laboratory experiments.

\section{INDOOR EXPERIMENT}

The measurement of scour depth at site is a difficult process, because it implies time and adequate equipment. Even with the apparatuses at hand, the deposition process, caused by the flood subsidence, may disturb the real scour depth value. To overcome this problem and with the purpose of analyzing the scour process caused by different boundary conditions, some laboratory experiments under a clear water state were conducted using the following apparatuses: tank, pump, sump, pipes, and a recirculating flume $(20 \mathrm{~m}$ long, $0.50 \mathrm{~m}$ wide, and $0.50 \mathrm{~m}$ deep) shown in Fig. 6. A 90-notch weir was used for measuring the discharge. In order to create a test section, a false bed was set on the bottom of the flume by means of wood plates. This section is formed by a recess $(0.75 \mathrm{~m}$ long, $0.50 \mathrm{~m}$ wide, and $0.20 \mathrm{~m}$ deep), filled with sand mixture, and located $12 \mathrm{~m}$ downstream from the water inlet (Fig. 7). During the experiments, the flow discharge and flow level varied from 5.0 to $20 \mathrm{l} / \mathrm{s}$, and from 4.5 to 16 $\mathrm{cm}$, respectively.

To conduct these experiments, the piers were varied in both size and shape. Three of these piers are cylindrical and vary in diameter $(3.42,4.82$, and $6.02 \mathrm{~cm}$ ). One is composed of two cylindrical piers, $4.82 \mathrm{~cm}$ in diameter, each. Except for the diameter, it is similar in shape and is a scale model $(1 / 100)$ to the real pier (Fig. 3). At different times, each pier was settled in the centerline of the test section and subject to the flow range above cited (Table 1). The ring of the compound pier was placed at the same level of the bed. To measure the scour depths, a point gage was mounted on the top of the flume in a carriage capable of moving in both cross sectional and longitudinal direction. For the compound pier three values of attack angles $\left(0^{\circ}, 30^{\circ}, 45^{\circ}\right)$ were used. Before each run, a blockage was set at the downstream end of the flume, for preventing the sand pool from being disturbed by the initial unsteady flow. Then, after the flowing water reaches a stable level, the sand pool was leveled and finally the blockage was removed, enabling the initiation of the scour process. Each run continued for a sufficient period of time until the equilibrium scour depth was attained.
Table 1 Conditions of the experiments.

\begin{tabular}{|c|c|c|c|}
\hline Mixture & $\begin{array}{c}\text { Discharge } \\
(1 / s)\end{array}$ & $\begin{array}{c}\text { Pier/ } \\
\text { Diameter }(\mathrm{cm})\end{array}$ & $\begin{array}{l}\text { Total of } \\
\text { Runs }\end{array}$ \\
\hline \multirow{2}{*}{$\begin{array}{c}\text { Uniform } \\
\mathrm{D}_{50}=1.42 \mathrm{~mm}\end{array}$} & \multirow{4}{*}{$5.0 \sim 20$} & $\begin{array}{c}\text { Circular } \\
3.21,4.82,6.02\end{array}$ & 35 \\
\hline & & $\begin{array}{l}\text { Compound } \\
4.82\end{array}$ & 105 \\
\hline \multirow{2}{*}{$\begin{array}{l}\text { Non-uniform } \\
D_{\min }=0.15 \mathrm{~mm} \\
D_{50}=2.2 \mathrm{~mm} \\
D_{\max }=5.0 \mathrm{~mm}\end{array}$} & & $\begin{array}{c}\text { Circular } \\
3.21,4.82,6.02\end{array}$ & 27 \\
\hline & & $\begin{array}{c}\text { Compound } \\
4.82\end{array}$ & 29 \\
\hline
\end{tabular}

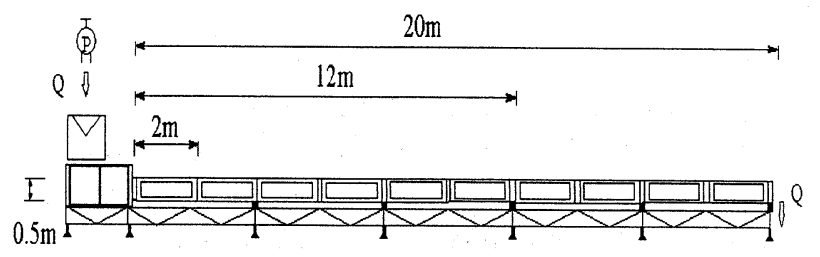

Fig. 6 Experimental flume

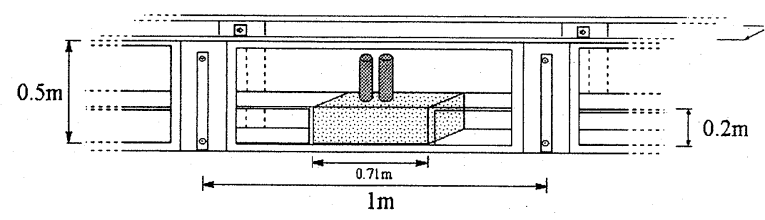

Fig. 7 Test section with the sand pool.

Later, the scour hole depth was measured and registered. The combination of discharges, flow depths, and attack angles led to several values of velocities and shear stresses and, consequently, a set of different values of scour depths. In order to conduct these experiments, two types of sand mixture were used: a) uniform sand, and b) nonuniform sand.

\section{1) Experiments using uniform sand}

In these sets of experiments, the influence on the maximum scour depth of factors as depth and velocity of flow, size and shape of the piers, and pier alignment was observed. The test section was filled with uniform sand, of which $D_{50}$ is equal to $1.42 \mathrm{~mm}$. The cylindrical piers were set at the center of the pool, at different times, and subject to the discharges cited before, resulting in 35 runs. Later, the single piers were replaced by the compound pier and the same range of flow discharge was applied. For this type of pier, the attack angle also varied, as stated before, resulting in a total of 105 runs.

\section{2) Experiments using non-uniform sand}

These experiments had the same objective as the previous one, but here the grading of the sediment mixture varied from fine sand to very fine gravel. From the size-frequency curve, the followings values were obtained: $D_{16}=0.85 \mathrm{~mm}, D_{50}=2.1 \mathrm{~mm}$, 
$D_{m}=2.2 \mathrm{~mm}$, and $D_{8 f}=3.2 \mathrm{~mm}$. This configuration resulted in a standard deviation, $\sigma_{g}$, equal to 1.88 . To compare the scouring at the model piers, a cylindrical pier $4.82 \mathrm{~cm}$ in diameter and the compound one were subject to the discharges above-mentioned, considering a zero attack angle. From this arrangement a total of 27 runs with single piers and 29 runs with compound piers were obtained.

\section{LOCAL SCOUR EVALUATION}

Among the factors affecting the equilibrium scour depth, flow velocity and depth are the quantities most easily measured. The influence of some other factors can only be analyzed either in qualitative terms or through physical models. Therefore, one should rely on the values of the measurable variables for determining the probable maximum scour depth. In order to verify a relationship that would describe the behavior of a scour process, several empirical equations have been proposed ${ }^{1)}$. Here, a non- dimensional number called $N s^{2}$ has been used to explain such behavior. This number is obtained as follows:

$$
N s=U / \sqrt{s g D_{g}}
$$

where $U$ is the mean flow velocity $(\mathrm{m} / \mathrm{s}), s$ is the sediment specific gravity (dimensionless), $g$ is the gravitational acceleration $\left(\mathrm{m} / \mathrm{s}^{2}\right)$, and $D_{g}$ is the typical grain diameter of the surface particle $(\mathrm{m})$.

\section{RESULTS AND DISCUSSION}

Before calculating the value of $N s$, the typical size grain diameter of the sand mixture should be provided. This is easily attained for a uniform mixture whose representative diameter is $D_{50}$. For some authors the best representative size for a sand mixture would be $D_{75}$ or $D_{80}{ }^{3)}$. However, they also stated that, the effective particle size problem is still unresolved and the user must select his own definition ${ }^{2), 3)}$. Because of this, several values have been proposed in the literature such as: $D_{50}, D_{m}, D_{16}$, $D_{35}, D_{40}, D_{65}, D_{84}$, and $D_{90}$. In the present work, these representative diameters were tested through the results from experiments with uniform/nonuniform sand and cylindrical piers. It was observed that the relationship $Z s / D \quad v s \quad N s$ from the experiments with non-uniform sand assumed the same pattern as the uniform one when $D_{84}$ of the sand mixture was used as representative. Considering that, apart from sand distribution, the values of the other parameters were the same in both case, and that $D_{8+}$ could be a suitable representative of a sand mixture ${ }^{3)}$, this diameter can be representative of this mixture. In addition, the results obtained for the experiments with uniform sand can be extrapolated, in a certain way, to the experiments with the non-uniform one. Henceforth, $D_{84}$ will be used as representative of the sand mixture and the results obtained will be discussed, considering the influence of the following factors: flow velocity, flow depth, pier size and shape, and pier alignment to the flow.

\section{Flow velocity}

The influence of this factor can be easily seen through the linear tendency obtained when the relative scour depth, $Z s / D$, is related to the dimensionless number, $N s$, considering as the representative diameter of the sand mixture the value of $D_{84}$, which shows a good correlation between these two parameters (Fig. 8). To verify the reliability of this statement, the same procedure was applied to the data from the compound pier. Different from the result displayed on Fig. 8, those from experiments with compound pier did not show a good relationship between the parameters (Fig. 9). These figures show that for a fixed height of the tail gate, the larger the flow velocity, the deeper the hole. For almost all the discharges applied over the uniform sand bed, the profundities of the scour hole were larger than those experimented with nonuniform one. This is explained by the fact that, as the standard deviation increased, the larger particle on the bed tended to protect the smaller ones, creating what is known as armor coat ${ }^{3), 4), 5)}$. In this situation, the larger particles, which are transported into the hole, create a coat that dissipates the flow energy and reduces the action of the downflow, resulting in small values of depth. Moreover, for small values of velocities the scour was much more pronounced at the lateral of the pier than at its rear in both sand mixtures. It is important to notice that, for the distribution shown in Fig. 8, the initiation of movement occurs for $N s$ equal to 0.96 . For the compound pier, the initiation of movement takes place at $N s$ equal to 1.3 (Fig. 9).

The tendency in Fig. 8 enables the development of a linear equation that provides the value of $Z s / D$ for a given value of $N s$ :

$$
Z s / D=A\left(N s-N s_{c}\right)
$$

where $A$ is equal to $0.66, N s c$ is equal to 0.96 .

Considering the $D_{8+}$ of the Shimanto riverbed, a flow velocity around $3 \mathrm{~m} / \mathrm{s}$, and a pier diameter equal to $4 \mathrm{~m}$, this equation gives a scour depth around $6 \mathrm{~m}$. 


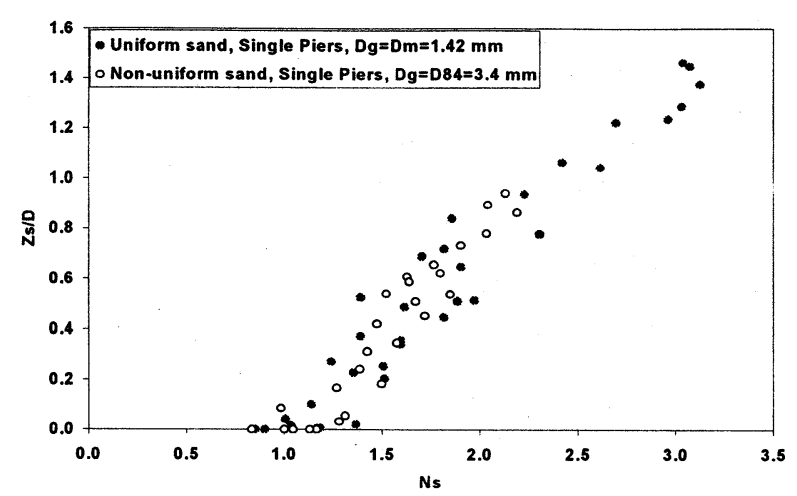

Fig. $8 \mathrm{Zs} / \mathrm{D}$ vs $N s$ for single circular pier and two different sand distributions (uniform and non-uniform).

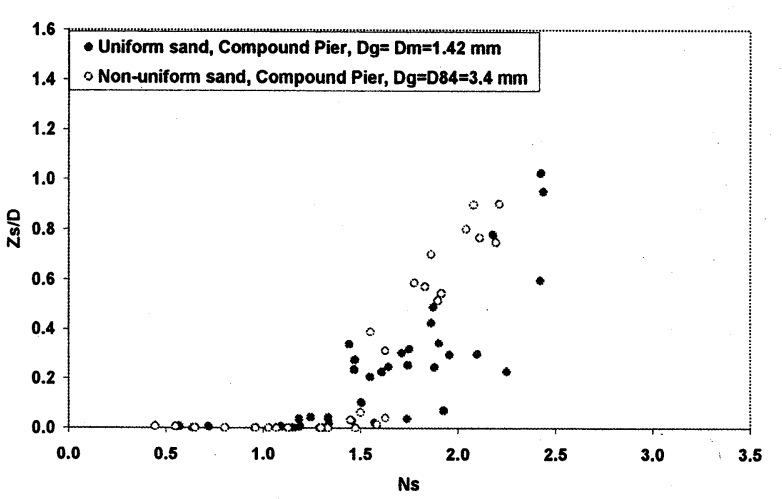

Fig.9 $Z s / D$ vs $N s$ for compound pier, attack angle $=0^{\circ}$, and two different sand distributions (uniform and non-uniform).

\section{Flow depth}

A number of formulas that provides the value of scour depth for a given flow depth is available in the literature ${ }^{1), 3), 4}$. However, when the data collected in these experiments were applied to these formulas or when this relation was tried out, no tendency between these two variables could be found. Considering that only clear water condition were studied, the results obtained lead us to believe that, for this scour condition, instead of flow depth, those factors that take into account the flow velocity as a parameter (Reynolds number, Froude number, Ns, among others) can better explain the scour phenomenon.

\section{Shape and size of the pier}

As for the shape and size of the pier, the results showed that scour increase with the width of the pier. However, for the compound pier, the values of scour depth were slightly smaller than those of single pier, even though the same flow discharge and height of the gate had been applied (Fig. 10).

Two probable factors can be the cause of this reduction: the longitudinal size of the compound pier, and the ring surrounding the cylinders.

Although the longitudinal size seems small (13 $\mathrm{cm})$, it is almost three times the size of the single pier $(4.8 \mathrm{~cm})$.

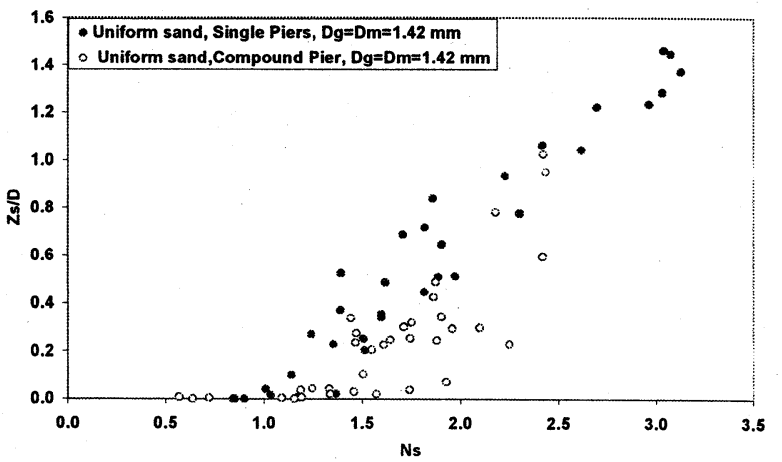

Fig. $10 Z s / D$ vs $N s$ for single and compound pier using a uniform sand and attack angle $=0^{\circ}$.

This creates a gap between the horseshoe vortex, at the upstream face, and the wake vortex, at the downstream face, decreasing the interaction of these two phenomena and consequently reducing the scour depth ${ }^{3), 4), 5 \text { ). }}$

In case of the ring, two different effects are identified. The first is to prevent up to a certain flow velocity the action of the downflow. Above a certain velocity, the ring will not influence on the scour process. The second effect is to create a fictitious pier width $(5.5 \mathrm{~cm})$, wider than the real diameter, $4.82 \mathrm{~cm}$ (Section 2.1, and 3.). Because of the ring, the scour process only commences when the flow acts on the upstream face and laterals of it, removing and transporting the bed material. Then when the scour hole forms and reaches the thickness of the ring, the width to be considered for the scour process is once more the diameter of the single pier. The first effect is benefic and can prevent scouring. The second one is harmful and can lead to the ruin of the structure.

\section{Pier alignment}

The other very interesting aspect is that, for a compound pier, an increase in the attack angle leads to an increase in the scour depth, even though the same flow discharge and depth is used. For this situation, the critical motion values vary according to the attack angle and for the same values of $N s$, the larger the attack angle, the deeper the scour depth. This is easily seen through the inclination of the tendency curve for different attack angles (Figs. 11, 12). For a zero attack angle, the scour process begins with the action of downflow at the rear face of the pier and propagates towards the upstream. This process will continue until the angle of the rim in the hole equals to the repose angle of the sand. For a superior attack angle, the scour begins on the left side of the rear face and on the right side of the downstream face. Then the scouring at the rear face propagates towards the downstream of the same side. 


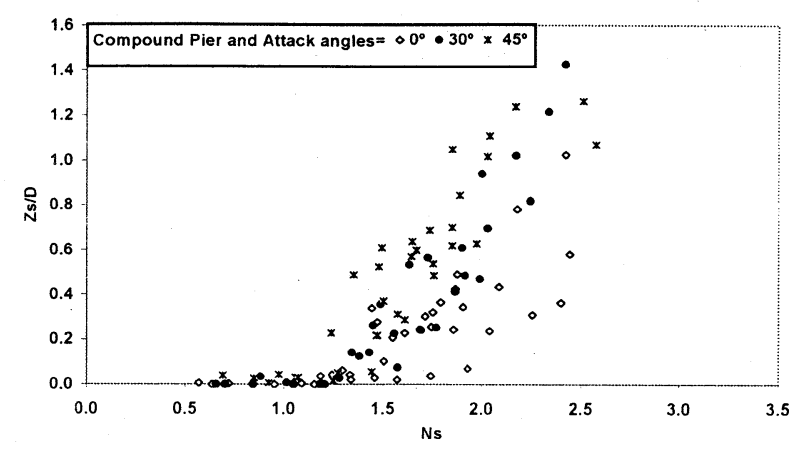

Fig. 11. Zs/D vs Ns for uniform sand and different attack angles.
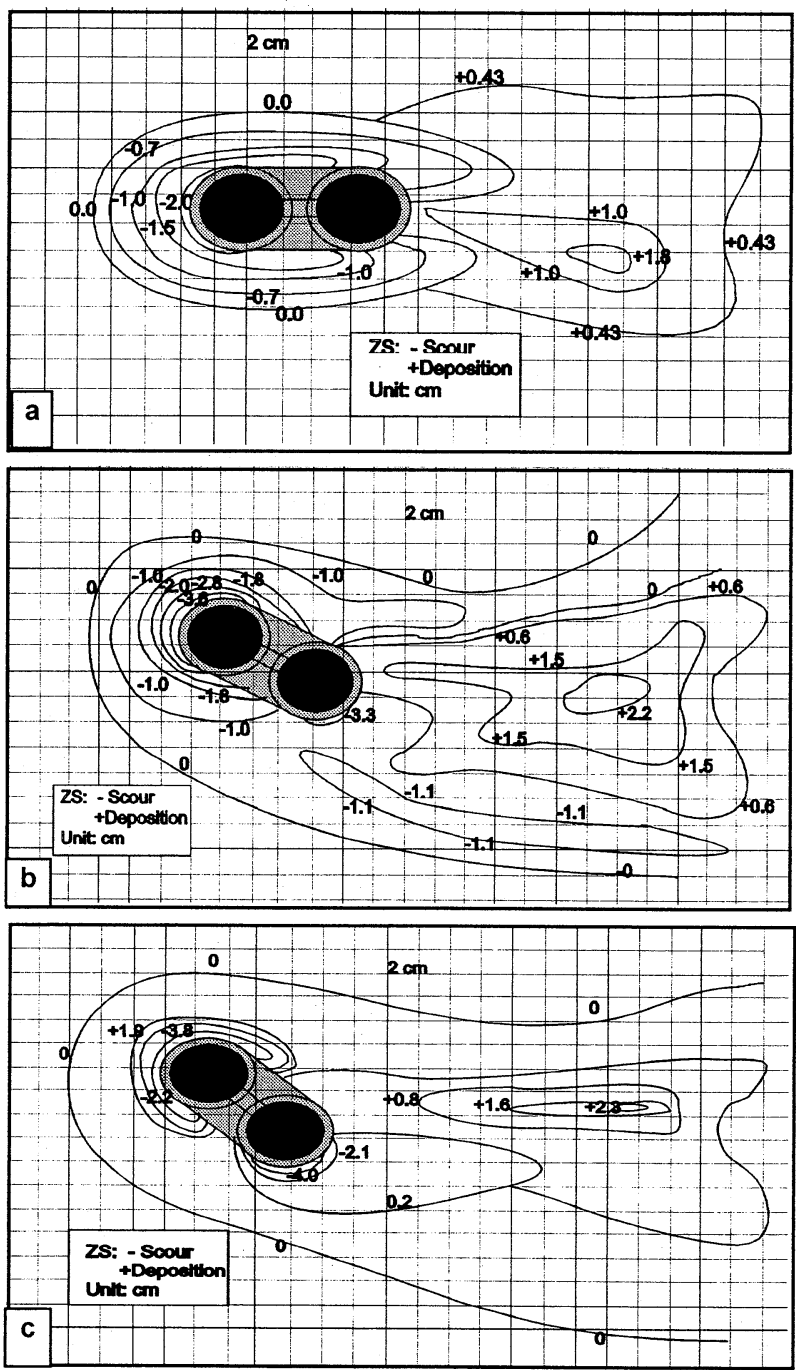

Fig.12 Contour of scour depth for different attack angles.

On the opposite side and at the downstream face of the pier, the scour process also occurs, but comparing the values at upstream and downstream, the former is stronger than the latter. The scour depth shape for different attack angles and velocity equal to $38 \mathrm{~cm} / \mathrm{s}$ is displayed on Fig. 12 a $(0), \mathrm{b}$ (30), and c (45). These figures also show that, according to the angle, the volume and area of the hole at the rear face increase and the eroded material is deposited somewhere downstream of the piers.
The extent of the hole toward the upstream of the pier varied from $5.5 \mathrm{~cm}$ (for 0-attack angle) to $7 \mathrm{~cm}$ (for $45^{\circ}$-attack angle).

\section{CONCLUSIONS}

To summarize, in order to analyze the scour process at the piers of Shimanto River Bridge, some laboratory experiments using uniform and nonuniform sand mixture have been conducted. Pier models with two different shapes and subject to several values of flow discharge were used, representing the situations usually found at bridge foundations crossing rivers. By using the data colleted, the representative diameter of the nonuniform mixture was determined, enabling the extrapolation of results from the experiments with uniform sand. Based on the results, it is possible to conclude that among the factors affecting on the scour process flow velocity and grain size exert an important role. This fact is seen through the linear tendency between $Z s / D$ and $N s$ found for single piers. However, for a compound pier the same value of $N s$ resulted in different values of $Z s / D$ what means that, apart from velocity other factors need to be considered. As for attack angle, the scour depth varies in magnitude according to the grade of alignment to the flowing water. The area and volume of the scour hole, upstream of the pier, increases with the attack angle and this enlargement can be source of problem if its is not controlled. The linear curve developed can be used as a first estimator for analyzing the scour depth due to a flood event.

\section{REFERENCES}

1) Johnson, P. A., Comparison of pier-scour equations using field data, Journal of Hydraulic Engineering, Vol. 121, No. 8, ASCE, pp626-629, 1995.

2) Simons, D. B. and Senturk, F., Sediment Transport Technology, Revised Edition, Water Resources Publications, Littleton, Colorado, 897p, 1992.

3) Breusers, H.; Raudkivi, A. J., Scouring. IARH Hydraulic Structures Design Manual. A. A. Balkema, Rotterdam, Netherlands, 1991.

4) Ettema, R., Mostafa, E. A., Melville, B. W., and Yassin, A. A., Local scour at skewed piers, J. Hydr. Engineering, ASCE, 124(7), 756-759, 1998.

5) Melville, B. W. and Coleman, S. E., Bridge Scour, Water Resources Publication, LLC., The University of Auckland Auckland, New Zealand, 550p, 2000.

(Received September 30, 2002) 